\title{
Heavy physical work under time pressure: the garbage collection service- a case study
}

\author{
Ilza Mitsuko de Oliveira Camada ${ }^{\mathrm{a}}$, Silvana Maria Santos Pataro ${ }^{\mathrm{b} *}$ and Rita de Cássia Pereira Fernandes ${ }^{\mathrm{a}, \mathrm{b}}$ \\ ${ }^{a}$ Departamento de Medicina Preventiva e Social, Faculdade de Medicina da Bahia, UFBA, Salvador, BA, Brazil. \\ b Mestrado em Saúde, Ambiente e Trabalho. Faculdade de Medicina da Bahia, UFBA, Salvador, BA, Brazil.
}

\begin{abstract}
The increased generation of garbage has become a problem in large cities, with greater demand for collection services. The collector is subjected to high workload. This study describes the work in garbage collection service, highlighting the requirements of time, resulting in physical and psychosocial demands to collectors. Ergonomic Work Analysis (EWA) - a method focused on the study of work in real situations was used. Initially, technical visits, global observations and unstructured interviews with different subjects of a garbage collection company were conducted. The following step of the systematic observations was accompanied by interviews conducted during the execution of tasks, inquiring about the actions taken, and also interviews about the actions, but conducted after the development of the tasks, photographic records and audiovisual recordings, of workers from two garbage collection teams. Contradictions between the prescribed work and activities (actual work) were identified, as well as the variability present in this process, and strategies adopted by these workers to regulate the workload. It was concluded that the insufficiency of means and the organizational structure of management ensue a situation where the collection process is maintained at the expense of hyper-requesting these workers, both physically and psychosocially.
\end{abstract}

Keywords: Urban Cleaning, Ergonomics, Psychosocial distress, Physical exertion.

\section{Introduction}

In modern society, the increase in consumption was accompanied by increased generation of garbage. In the year 2006, at the city of Salvador, which had a population of $2,892,625$ inhabitants, $1,373,322$ tonnes of garbage were collected, $53 \%$ of which from domestic solid waste and street sweeping [5]. This increasing production of garbage has become a problem in large urban centers, leading to increased demand for public garbage collection services. In such a system, the garbage collector is an important actor, and his body is turned into a tool used to carry garbage [19].

In scientific literature about the garbage collector activity, the predominant focus is on workplace accidents and exposure to occupational hazards. The main factors involved are improper packaging of piercing-cutting garbage, and lifting and carrying of weight [20]. Although work-related accidents involving garbage collectors are often reported in scientific literature, the characteristics of work, tasks and characteristics of personnel management are not always addressed. The real conditions of work are not known trough these studies.

Working involves physical, cognitive and psychological aspects, which can cause distress, depending on its demand levels. Execution of tasks under time pressure is a situation that reveals these aspects, being associated with the development of musculoskeletal disorders. Based on that, this study aims to describe the work at a garbage collection service and time restrictions in the execution of tasks, originating physical and psychosocial demands to workers.

\footnotetext{
* Corresponding author. E-mail: silpataro1@hotmail.com. Address: Rua Prof. Isaías Alves de Almeida, 242/302-A, Salvador, BA, Brazil. Zip/Postcode: 41760-120.
} 


\section{Methods}

This study was conducted in a garbage collection company in Salvador, Brazil. Data collection occurred between April and July 2010 and used Ergonomic Work Analysis (EWA) as a methodological reference. EWA is a method centered on the study of the activity, observing, recording, analyzing and understanding real situations of work [7]. The method allows the identification of work organization, work determinants and process variability, evaluating the skills and mechanisms used by workers to achieve the goals $[3,4]$.

Among the central distinctions of EWA, the concepts of task (prescribed work) and activity (actual work) are highlighted. The first refers to what is prescribed by the company, considering the objectives to be achieved, expected results specifications, means provided and general working conditions. The activity is how the individual deals with the proposed objectives, organization of work and the means provided to execute the task [7]. The distance between task and activity is due to variability - derived from the characteristics of the worker, and from production system $[1,7]$.

Workers are faced with restrictions or limitations in the development of their tasks. In situations where there is greater room for maneuver, the individual can change goals or means in order to complete tasks without damaging their health. However, in more restrictive situations, such regulations (of objectives and means) can not be adopted. As a consequence, the required results are achieved through modifications of the workers' physical or mental state, with fatigue or weariness, and may result in loss of health. If the difficulties in performing the tasks are maintained, workers will no longer be able to achieve their goals, regardless of the operating mode adopted [7].

The EWA assumes the presence of researchers in the workplace, observing the situations and the interaction between the observed behaviors and reports from workers about these behaviors [11]. Observation alone is not sufficient to explain the reasons for what is observed. This can be possible through what is said by workers because they assign a meaning to what is observed. Similarly, analysis based only on discourse is not viable because it is not able to reveal the tacit knowledge, which is often "automated" by the worker, and put in place subconsciously [11].

\subsection{Development of the ergonomic study}

Initially there were technical visits and unstructured individual interviews with different subjects from the company, aiming to approach the field of study; gather information about operation and organization of production; identify the determinants of the task of garbage collection, according to the approach proposed by Guerin et al.[7].

After five hours of global observations, it was stressed in the discourse of respondents the importance attributed by the company to performing tasks without exceeding the regular work hours, aiming to reduce the occurrence of overtime, and reduce costs. Faced with this demand, it was elaborated the hypothesis that there was an incompatibility between the requirement to comply with the daily working hours and the completion of the task, that could lead to more or less efficient regulations performed by the garbage collection team. This assumption guided the systematic observations, which were carried out over a period of 23 hours, with interviews conducted during the execution of tasks, that is, in the work situation, inquiring about the actions taken, and also interviews about the actions, but conducted after the development of the tasks and, after the first contacts with the workers, audiovisual recordings and photographic records. The results of the observations and the information collected from the managers and workers were recorded in a field diary.

In the systematic observations step, eight workers from two different garbage collection teams were accompanied, each team consisting of one driver and three garbage collectors.

This study was approved by Hospital São Rafael Ethics in Research Committee, according to Resolution 196/96, which was established by Ministry of Health Ethics in Research Committee.

\section{Results and discussion}

The subject company of this study provides outsourced urban garbage collection services in the city of Salvador, accounting for 12 of the 17 cleaning nuclei of Bahia's capital city. The company has 1,943 employees working in cleaning services, of which 118 are drivers and 367 are garbage collectors. 


\subsection{On tasks and operations in garbage collection}

The collection team, called "garrison", consisting of a driver and three collectors, has an eight-hour workday, with a weekly paid rest day.

Of the two teams observed, one went through a single itinerary, while the other would go through two itineraries alternately, each with distinct characteristics. In one of the itineraries of the second team, the area had the highest population density, highest number of houses (whose residents had lower incomes) and businesses, where poor condition city-owned garbage collection equipment predominated. However, in the other itinerary, the covered area had lower population density, greater purchasing power of residents, few commercial establishments, and houses of larger dimensions. Most of the garbage collection equipment was privately held and was in better condition. As for the first team, it went through an itinerary similar to the first itinerary of the second team, previously described.

At all the itineraries observed, the volume of garbage is variable, characterizing seasonality, being higher on Mondays and Tuesdays. This happens because the collection serves main streets only on weekends, not including small secondary streets, with consequent accumulation of garbage from these days. During the summer, due to the increased number of people in the city - caused by the influx of tourists -, this volume also increases.

These differences present in the itineraries require that the collectors adapt to changes frequently, either with respect to the geography of the streets, or with respect to garbage quantity, content and type of packaging. Each itinerary has its own characteristics, that require different operational modes and skills from workers, in order to deal with disturbances in certain situations and achieve the goals set, in accordance with what is also referred by Santos et al. [16] and Abrahão and Torres [2].

Each garrison collects garbage along an itinerary of streets and pre-defined truck emptying sites (sanitary landfill or municipal transshipment station). The operation of emptying the truck is called "leakage".

The collectors are supposed to pick up the garbage in front of houses and shops, place it at the trunk of the (compactor) truck, and activate the compactor - to press the garbage. In order to perform their task, they must collect the garbage - stored in plastic bags, barrels made of iron or hard plastic, two-wheeled containers and four-wheeled containers, in addition to performing the sweeping, which consists in gathering the garbage in small piles, and then moving them to the trunk using tools such as forks, brooms and rakes (Figure 1). They perform these actions at an itinerary that shall be covered within an eight-hour shift, except on Mondays and Tuesdays, as a collector reveals:

"The company demands the fulfillment of the schedule... they know that on Monday and Tuesday the difficulty is higher... but from Wednesday on, they begin to demand..."

The places where the team will suspend collection to empty the truck must be the sites that were previously defined by production managers. The number of trips to "leakages" should not exceed the prescribed quantity, which is three on Mondays and Tuesdays, due to the increased volume of garbage, and two on the other days of the week.

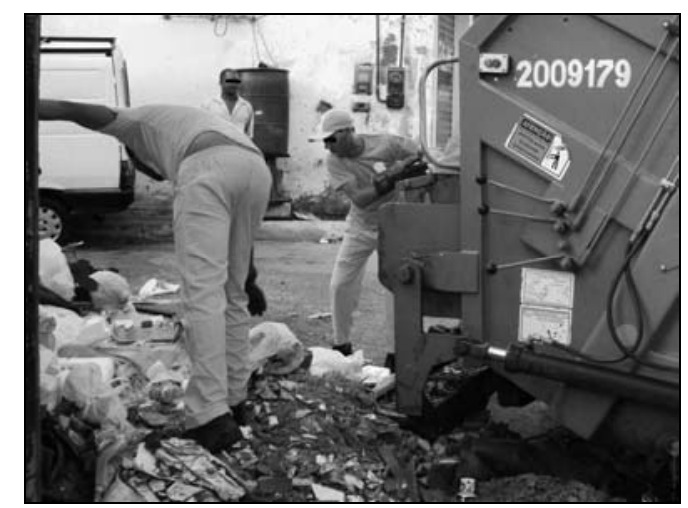

Fig. 1: Collectors picking plastic bags up

The driver is considered the head of garrison, and so is seen by other team members. The driver must regulate the load, the number of "leakages" and the waste removal pace, besides executing other tasks.

\subsection{Contradictions between the demands of production managers and performance under real operating conditions}

For the garrison to be well rated by managers, the number of pre-defined "leakages" shall not be exceeded and the collection shall be completed within the daily working hours, leaving no waste, and generating no overtime. It was observed the demand that the driver is aware of the pre-defined number of "leakages" and the load at the truck, avoiding exceeding the maximum load, in order not 
to generate greater mechanical wear to the vehicles. That is, on one side, the driver must account for the preservation of the vehicle; on the other, he shall regulate the number of "leakages", avoiding delay in the collection completion and, therefore, extension of the workday. This double requirement originates more restrictions, becoming incompatible, and generating friction between workers. It was observed that the driver tries to fulfill the requirements imposed, going against the collectors, who prefer to slightly exceed the truck's load, delaying the leakages, in order to carry a greater amount of waste per trip, reducing the delay in itinerary completion. That situation is evidenced in the following testimony of one of the collectors:

"Today, if we make three trips ["leakages"], it will end at four to six o'clock in the afternoon. If we make two trips, we finish early ... let's see if it happens ...".[However, after discussing the matter with the driver, he decides to make three leakages, in order not to overload the vehicle].

It is made explicit a contradiction between the rules of the company and the reality of work, originating psychophysical wear of the collection team.

Pursuing the fulfillment of collection within the daily working hours determines a psychosocial demand. In order to meet this company requirement, the garbage collector performs its activities at accelerated pace.

Although it is not an explicit recommendation of the company, usually the collectors give up enjoying the one-hour lunch period, which they are legally entitled, in order not to delay collection. This situation can be evidenced from the testimony of a collector:

"If everyone here take a one-hour lunch break, it delays. [If that happens] they get rid of us, hire another one...".

As a way to regulate this restriction, the collector that accompanies the driver at the "leakage" eats the meal in the truck cabin while traveling; those who remain at the itinerary eat quick snacks, and soon resume collection. This action is not prescribed, nor is it recognized by production management as a strategy that shows commitment to task completion.

In addition, the driver influences the collection pace, modulating it. An example is driving faster, requiring collectors to toss the bags in the trunk while they run. He also intervenes when the garrison spends too much time on a particular operation, by producing an audible signal - pressing the "gas pedal" when the truck is not moving. However, such attitudes are not viewed with disfavor by the collectors, since they believe that the faster the truck, the sooner they will complete the collection:

"We like drivers that speed, right... we're used to that... or else we stay late...".

At first, the above testimony could be misunderstood, considering that the faster the work pace, the greater the physical and cognitive demands for the collectors themselves. However, that discourse from the collector becomes clear through systematic observation of the work situation, as follows.

It was found that the population throws the garbage out at any time of day, so there is progressive accumulation. With that, the longer the collectors remain in the itinerary, the greater the volume to be collected. If the garrison goes through a part of the street that was already collected and there is "new" garbage, it has to re-do collection. Otherwise, there may be complaints from residents, and the supervisor who oversees the itinerary can apply sanctions. Thus, it is made clear the incorrectness of attributing working hours extension and consequent generation of overtime - to the collectors. It was found that the occurrence of these arises from the demands of work, with the increased volume of garbage.

According to collectors, the physical and mental burden at work is so significant that the money they receive for overtime is not sufficient compensation. As already stated, the longer they remain at the itinerary, the greater the amount of garbage to be collected; consequently, there will be increased psychophysical wear and decreasing of the rest period before the next working shift. It is known that an insufficient rest period is an important factor for physical wear and the onset of musculoskeletal complaints [9].

Thus, the idea - widespread in management that the garbage collector would be responsible for extending his working hours was not verified. That is, the conception that it would be advantageous for the collectors to extend their working hours in order to have monetary gain did not support itself. Some collectors statements also reveal the inconsistency of this conception from management:

"For me it's not worth [overtime] ... we work more, we wear out... it's very tiring ... some days wake up and don't even want to come to work ... " 
".... for us, it's tiring [overtime] ... on the other day we have to wake up early again, we don't even have time to rest all right".

As teams of different shifts use the same trucks, if a garrison delays the work completion, the next one starts the collection delayed, triggering a cascade effect. Each delay in starting a itinerary results in a more restricted period of time for the next garrison to complete the tasks.

In addition, the truck can get damaged, and so the garrison has to wait for it to be repaired, as there are few reserve trucks. Due to poor maintenance conditions of the latter, some drivers prefer to wait for the impaired vehicle to be fixed. This choice stems from the tacit knowledge of the driver, as evidenced below:

"The reserve cars are the worst... I only use when the repair of the other [the damaged one] takes long.. we must work something out... when the automatic gas pedal breaks, we have to accelerate continuously, without rest to the foot... we have to choose the reserve car according to the itinerary... if it has too many slopes, we can't use cars that don't accelerate. If you have a lot of garbage, you can't use one without brakes."

Sometimes the inhabitants tie the barrels to lampposts or grates with chains, so they are not stolen or removed to distant locations. This causes more difficulties to the garbage collectors, who have their movements limited when pouring the contents of these reservoirs into the trunk.

Poor maintenance of collection equipment is another common adversity. Most containers have defective wheels, or even no wheels. As a result, collectors have to drag them to the truck, requiring great physical effort.

Many four-wheeled containers have defects in the part that fits in the truck, preventing its mechanical unloading. In order to circumvent this, some collectors use a rope or piece of rubber, twining the fitting, in order to stabilize it and allow greater control to the container descent speed after emptying it in the trunk. However, this procedure is banned by the occupational safety department, which considers it an unsafe act, stating that the rope or rubber does not provide sufficient stability and can cause accidents. Thus, the department directs the collectors to dump the contents of the container at the ground and then transport them to the truck manually, with the aid of tools, or else leave the site without collecting. However, this requirement, from safety department, is incompatible with the requirements of the collection, revealing a contradiction, evidenced in the following testimony:

"The safety technician says that we should not "get" [when the container is defective], we should leave there, but the inspector says it is to get... otherwise the city fines the company. So, anyway, we have to get..."

Thus, workers prefer not to follow the directions of the safety department, even at risk of punishment. Collecting the contents manually implies a greater burden of work and increases the task duration, possibly hampering the fulfillment of the task within the regular working hours. The direction of leaving the container in place, without collection, is contrary to the prescription of urban cleaning itself. Working under real operating conditions, the collectors can not comply with safety regulations in order to make collection feasible, even at unsafe conditions. The contradiction between the normative and the real is made explicit.

Collectors who do not use the rope - for fear of the safety department - try to stabilize the four-wheeled container and control its descent speed by grasping and pulling the side handles with one hand, and supporting the other hand in the fitting. That is, even when they do not use the rope, in an attempt to comply with the safety regulations, the collectors develop other strategies using their body as a way to accelerate the collection process. This decision unfavors the worker's health, for it generates great exertion and muscular overload of the upper limbs. Also, there is imminent danger of accidents in this operation. This reveals the normative conception of safety, that instead of contributing to feasible solutions in real work situations, is limited to prescribe what in this case is incompatible with the completion of the task and its requirements. To Llory [12], the safety doctrine does not take into account the distance between prescribed work and real work, which requires constant regulation from the worker. This doctrine only simplifies, schematizes and reduces the reality of work, making safety procedures often insufficient.

The presence of disturbances in the work process requires continuous intervention and attention of the worker. Thus, it represents strong cognitive demand at a fast pace (psychosocial demand) and presence of intense physical demand [6], which contribute to the occurrence of loss of health and, in particular, musculoskeletal symptoms [13].

Amid the contradictions observed, control mechanisms carried out by managers were registered. In the form of punishment, they can be verbal 
reprimands, suspensions and even removal from the itinerary, the collector being transferred to the reserve.

As discussed by Santos et al. [16] and Vasconcelos et al. [17], when a collector is denied a fixed itinerary, his appropriation of work is rendered unviable, for it is prevented the accumulation of experience based on knowledge of local geography and in affective ties established within the team and with the community, which are important factors in the structure of workgroups. This impaires his ability of managing usual and unforeseen events, besides the conflicting goals of quality, time, safety and sparing the body, being subjected to increased workload and to situations of risk and psychological wear.

\subsection{Other group strategies adopted in order to complete the task}

The collectors use the garbage "reduction" technique to make the collection faster. In this strategy, one of the collectors is separated from the rest of the garrison, moving through shortcuts to a point forward in the itinerary, and makes big piles of garbage bags. Subsequently, the rest of the team hops off the truck only at the places where the garbage is "reduced" (disposed in piles), the truck remaining at a standstill while the reduced garbage is collected. When asked about the "reduction", a collector pointed out that it makes the collection progress, for it can be carried out between trips to truck emptying, saving time to finish the task. In accordance with the findings of this study, Vasconcelos et al. [18] also argue that by adopting the strategy of garbage "reduction", the collectors regulate their workload, because the worker that reduces the garbage can walk, and those who collect the reduced garbage do not need to run and throw the bags, keeping pace with the moving truck.

Collectors can extract, from the garbage itself, tools that accelerate the collection and promote higher quality to it-. An example is the use of large pieces of canvas, plastic or cardboard found in the garbage collected (Figure 2). During the "reduction", the collector goes through the street, placing the bags on top of one of these materials. He drags it until the volume becomes large or heavy. Then he pours its contents in some locations, thus forming piles of reduced garbage. This shows know-how, resulting in greater ease in task execution, with improvisation of tools out of materials found in the trash, but that are not always available.
Another strategy is to transport small volumes of garbage using two pieces of wood, taken from the trash. This technique is called "support", being executed to gather small amounts of garbage that abound after collection operations (Figure 3). In this way, workers can minimize contact with piercing-cutting materials, avoiding accidents, while improving the quality of the collection. This strategy is another expression of know-how, developed from experience, practical knowledge and tacit skills, which are effective and time-saving, and that when used in the context of safety are considered "prudence know-how" (savoir-faire de prudence) [12].

In addition to make the collection service agile and contribute to its quality, the strategies mentioned above are regulatory mechanisms that reduce the physical wear of the collectors and the risk of accidents with piercing-cutting materials, which is in accordance with what Guérin et al. [7] discuss.

\subsection{On the use of the body and some effects on health}

The collection work is done at a fast pace and without scheduled breaks. Just taking the example of musculoskeletal disease in the vertebral column, it is known that brief periods of rest, while performing heavy work, can lower intradiscal pressure and muscular fatigue $[14,15]$. Fatigue induces a change in muscle recruitment pattern, leading to sudden movements and poorly controlled efforts that can damage body structures [13].

At a number of garbage collection activities, workers adopt a trunk flexion over 90 degrees, which associated with load handling, rapid movements and constant rotation and leaning of the trunk, originate a greater burden on the lumbar region $[13,15]$.

During handling of containers or barrels, collectors perform constant movements of pushing, pulling and lifting loads, described in literature as giving rise to high peaks of compressive force in the lumbar column [10]. These workers are also exposed to whole body vibration during the itinerary, when seated inside the truck cabin or when standing on the footboard, this aspect aggravated by the poor condition of the streets [10]. These actions generate biomechanical overload, which is seen as an important risk factor for musculoskeletal complaints $[13,15]$.

Moreover, as reported by Vasconcelos et al. [17], the work of a garbage collector requires constant 
attention, because the individual must make decisions all the time, whether regarding his safety or the team safety; concerning handling of garbage. These factors may contribute to psychosocial distress at work and consequently to the worsening of musculoskeletal symptoms $[8,13]$.

It was found that there are physical and psychosocial demands, with excessive pressure and control by management, work overload and the need to adopt strategies that, sometimes, involve conflict with safety regulations, in order to achieve work objectives. Thus, the demanded results are achieved only through hyper-requesting the worker physically and mentally [2,7].

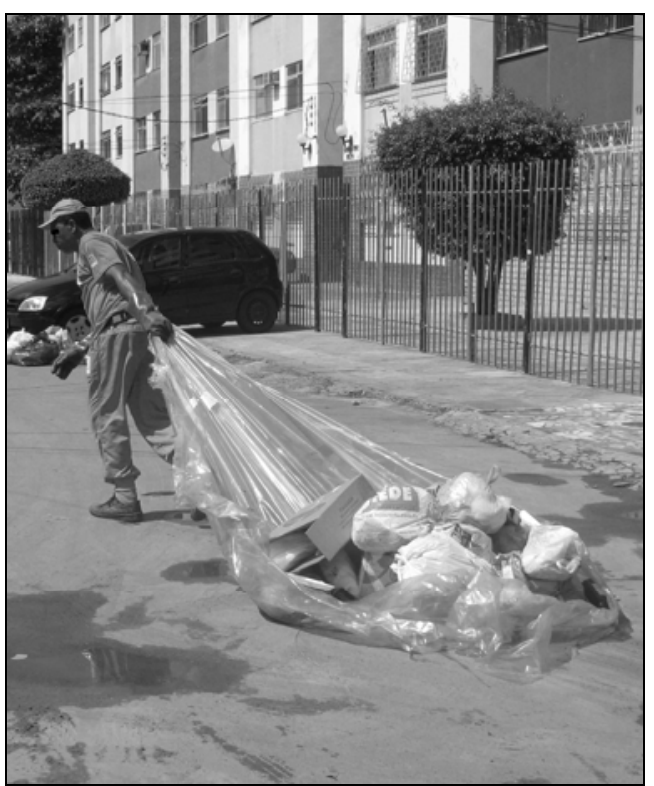

Fig. 2: Collector using a piece of plastic to collect garbage

\section{Final thoughts}

Through ergonomic work analysis, this study identified the differences between prescribed work and activities (actual work) in a domestic garbage collection service. The distance between them, highlights the variability of the process and the demands to collectors, revealing important contradictions between the normative and practical, sometimes irreconcilable. Therefore, we emphasize the incompatibility between the requirements, by production managers, that the garrison completes the collection task without extension of the preestablished working hours.
Garbage collectors execute work in which physical and mental overload are present, being characterized by the need to manage restrictions, since they are subjected to adverse situations. These restrictions can be triggered by time pressure, associated with insufficiency of means of production and also with work organization.

Given this confrontation, the collectors need to develop strategies, generally not recognized, based on variability management and group work. Through these, they try to regulate workload and restrictions, in order to ensure the efficiency of collection and preserve, to some extent, their health. However, under time pressure and in situations of limited room for maneuver, the workers often need to disregard the normative to achieve their goals, resulting in distress and impossibility of preserving their health, in spite of the regulations adopted.

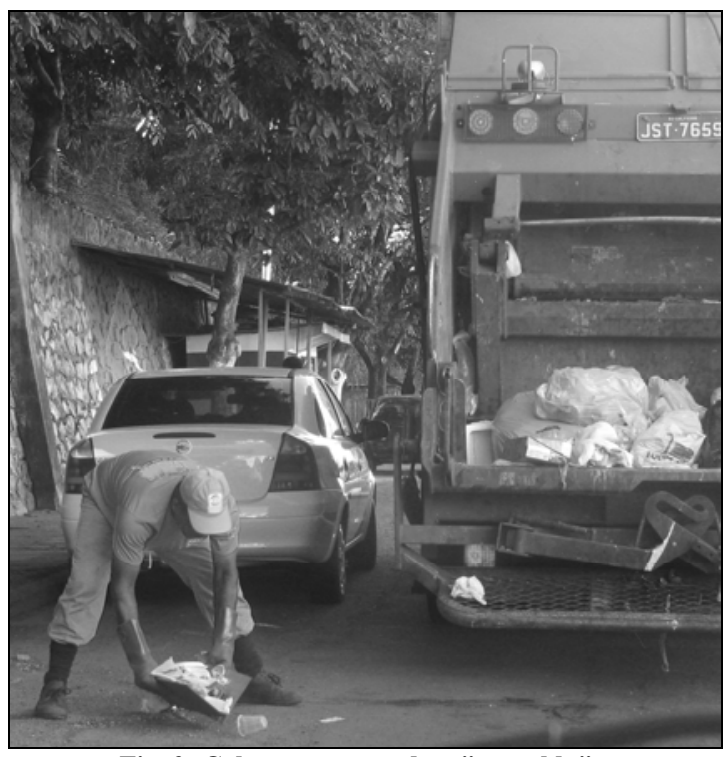

Fig. 3: Coletor executando o "respaldo"

\section{References}

[1] J.I. Abrahão, Reestruturação produtiva e variabilidade do trabalho: uma abordagem da ergonomia, Psicologia: Teoria e Pesquisa 16 (2000), 49-54.

[2] J.I. Abrahão and C.C. Torres, Entre a organização do trabalho e o sofrimento: o papel de mediação da atividade, Revista Produção 14 (2004), 67-76.

[3] A.V. Assunção, A cadeirologia e o mito da postura correta, Revista Brasileira de Saúde Ocupacional, São Paulo, 29 (2004), 41-55. 
[4] A.V. Assunção, Trabalho ou gestos repetitivos? Implicações na análise dos riscos biológicos, Anais do VI Congresso Latino Americano de Ergonomia da Associação Brasileira de Ergonomia, 2001, Gramado, Brasil.

[5] BAHIA. Secretaria Municipal de Serviços Públicos de Salvador. Plano Básico de Limpeza Urbana e Manejo de Resíduos Sólidos de Salvador. Salvador: SESP, 2007. Disponível em: <www.limpurb.salvador.pub.gov.ba.br/>. Acesso: junho 2009.

[6] R.C.P. Fernandes, A.A. Assunção and F.M. Carvalho, Tarefas repetitivas sob pressão temporal: os distúrbios músculoesqueléticos e o trabalho industrial, Revista Ciência e Saúde Coletiva, 15 (2010), 931-942.

[7] F. Guérin, A. Laville, F. Daniellou, J. Duraffourg and A Kuerguelen, Compreendendo o trabalho para transformá-lo. A prática da ergonomia, ed., Edgar Blücher, São Paulo, 2004.

[8] W.E. Hoogendoorn, P.M. Bongers, H.C.W. de Vet, I.L.D Houtman, G.A.M. Ariens, W. Van Mechelen, L.M. Bouter, Psychosocial work characteristics and psychological strain in relation to low-back pain, Scandinavian Journal of Work, Environment \& Health, 27 (2001), 258-67.

[9] A. Kilbom, Intervention programmes for work-related neck and upper limb disorders: strategies and evaluation, in: Effect of job rotation on need for recovery, musculoskeletal complaints: a prospective study among refuse collectors, P.P.F.M. Kuijer, A.J. Van der Beek, J.H. Van Dieë, B. Visser and M.H.W. Frings-Dresen, American Journal of Industrial Medicine, 47 (2005), 394-402.

[10]P.P.F.M. Kuijer and M.H.W. FringS-Dresen, World at work: refuse colletor, Occupational Enviroment Medicine, 61 (2004), 282-286.

[11]F.P.A. Lima, A ergonomia como instrumento de segurança e melhoria das condições de trabalho, Anais do I Simpósio Brasileiro sobre Ergonomia e Segurança do Trabalho Florestal e Agrícola, 2000, Belo Horizonte/Viçosa, Brasil.

[12]M. Llory, Acidentes industriais: o custo do silêncio. Operadores privados da palavra e executivos que não podem ser encontrados, ed., Multimais Editorial, Rio de Janeiro (199), pp. 1-320.

[13]NATIONAL RESEARCH COUNCIL \& INSTITUTE OF MEDICINE [NRC \& IM] Musculoskeletal disorders and the workplace: low back and upper extremities, Panel on musculoskeletal disorders and the workplace. Commission on behavioral and social sciences and education. Washington, DC: National Academy Press, 2001.

[14]J. Oliver and A. Middleditch, Postura in: Anatomia funcional da coluna vertebral, J. Oliver and A. Middleditch ed., Revinter, Rio de Janeiro, 1998, pp. 293-313.

[15] M.H. Pope, K.L. Goh, M.L. Magnusson, Spine ergonomics, Annual Review of Biomedical Engineering, 4 (2002), 49-68.

[16]M.C.O. Santos, F.P.A. Lima, E.P. Murta, G.M.V. Motta, Desregulamentação do trabalho e desregulamentação da atividade: o caso da terceirização da limpeza urbana e o trabalho dos garis, Produção, 19 (2009), 201-213.

[17]R.C. Vasconcelos, F.P.A. Lima, A.C.M.S. Abreu, R.C.R. Silva, J.A. Camarotto and A.O.S. Coutinho-Filho, Aspectos da complexidade do trabalho de coletores de lixo domiciliar: a gestão da variabilidade do trabalho na rua, Gestão e Produção, 5 (2008), 407-419.

[18]R.C. Vasconcelos, F.P.A. Lima, A.C.M.S. Abreu, R.C.R Silva, J.A. Camarotto and E.P. Murta, A estratégia de "redução" e a carga de trabalho dos coletores de lixo domiciliar de uma grande cidade: estudo de caso baseado na Análise Ergonômica do Trabalho, Revista Brasileira de Saúde Ocupacional, 33 (2008), 50-59.
[19]M.P. Velloso, E.M. Santos and L.A. Anjos, A coleta de lixo domiciliar na cidade do Rio de Janeiro: um estudo de caso baseado na percepção do trabalhador, Ciência \& Saúde Coletiva, 3 (1998), 143-9.

[20]M.P. Velloso, E.M. Santos and L.A. Anjos, Processo de trabalho e acidentes de trabalho em coletores de lixo domiciliar na cidade do Rio de Janeiro, Brasil, Caderno Saúde Pública, 13 (1997), 693-700. 